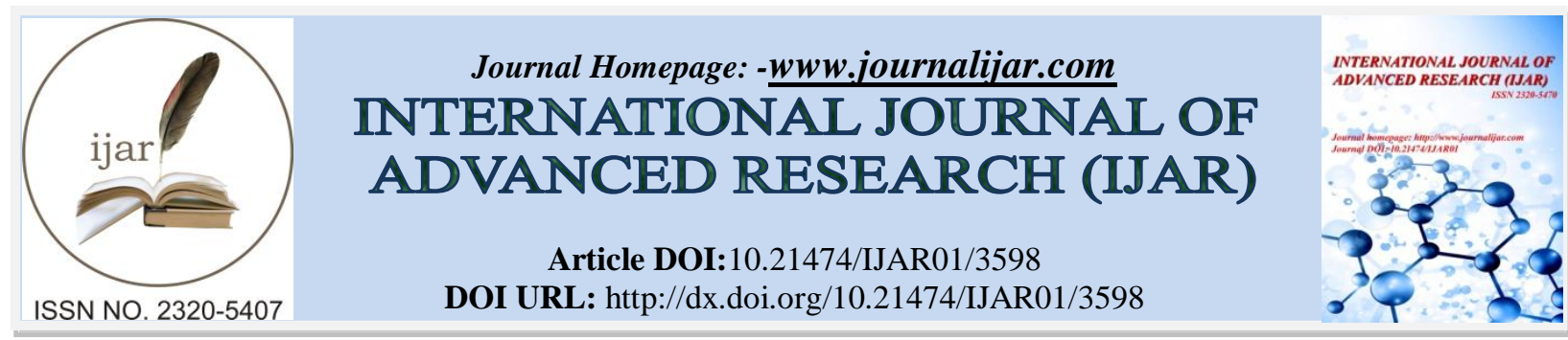

RESEARCH ARTICLE

\title{
GALLERY WALK TECHNIQUE IN TEACHING SELECTED TOPICS IN ENGLISH AND LEARNERS' PERFORMANCE.
}

Consorcia S. Tan ${ }^{1}$ and Ma. Concepcion Nathalie B. Alcantara ${ }^{2}$.

1. Laguna State Polytechnic University Los Baños Campus, Laguna, Philippines.

2. Bay Central Elementary School, Laguna, Philippines.

\section{Manuscript Info}

Manuscript History

Received: 05 January 2017

Final Accepted: 10 February 2017

Published: March 2017

Key words:gallery walk, technique, teaching, performance

\begin{abstract}
The study aimed to determine the effectiveness of Gallery Walk Technique in teaching selected topics in English among Grade Four learners. The hypothesis stating that there is no significant difference between the performance of the experimental and control groups was tested at .05 level. Quasi-experimental research was adopted by the study employing match-pairing of participants. Pre-test was administered to the learners and scores utilized to identify the matchpairs. T-test for independent means was employed to determine if there is a significant difference between the performance of the two groups. For two quarters, the experimental group was taught using Gallery Walk Technique whereas the control group was taught using traditional method. Formative tests were administeredduring the implementation of the study. Post-test was given after implementing the two methods of teaching. Results revealed that there was a significant difference in their performance. The experimental group performed better than the control group.
\end{abstract}

Copy Right, IJAR, 2017,. All rights reserved.

\section{Introduction:-}

English is a learning area in elementary level in the Philippine educational system. Pupils' performance is gauged based on the results of the National Achievement Test (NAT) administered yearly by the Department of Education. The test aims to provide empirical information on the achievement level of students at certain grade levels. The low Mean Performance Scores (MPS) in English of pupils from 2009-2013 (DepEd, 2013) specifically in reading and grammar indicated that the teaching of English is very much wanting of improvement.

The primary purpose of teaching at any level of education is to bring a fundamental change in the learner. To facilitate the process of knowledge transmission, teachers should apply appropriate teaching methods that best suit specific objectives and level exit outcomes. Identified teaching strategies all over the world are the visual aids, modelled spoken language, lesson outlines, skim and scan, and the like contingent on the set curriculum to improve pupils' performance. Because teaching and learning now come in different styles and forms, educators need to try on adopting new methods in teaching and learning which aim at improving the quality of education. Although some teachers shudder at the thought of having all of the students out of their desks moving around the classroom at the same time, but in reality, it can be a very effective technique for classroom management especially in the elementary level. Meyers, et al (1993) consider active learning as learning environments that allow students to talk 
and listen, read, write and reflect on course content. This is enhanced through informal small groups, simulations, problem-solving exercises and other activities.

Stewart (2009) cites in his theory of basic learning that learners had their foundation in English at the elementary level and enhanced in the high school level. Bloom, et al. (1956) in his Taxonomy of Educational Objectives said that students proceed from a lower level of learning such as remembering concepts, comprehension and application to a much higher level. Mastery of the lower level should be achieved first before they are able to analyze and evaluate concepts, processes and procedures.

The five skills of English as a discipline such as reading, listening, speaking, writing and viewing need to be amplified. Effective teaching for tomorrow demands teaching strategies in which teachers creatively organize a variety of content which must be taught to a variety of learners with different backgrounds, needs and interests. Compared to traditional methods, multi-sensory integrated strategies make pupils more enthusiastic, thereby more motivated to learn. Gagne's (1985) Conditions of Learning Theory asserts that there are several different types or levels of learning. He identified five major categories of learning: verbal information, intellectual skills, cognitive strategies, motor skills and attitudes. All categories of learning cited by Gagne are included in the Gallery Walk.Gallery Walk technique encourages students out of their chairs and actively involve themselves in the discussion. Tewksbury, et al. (2014) cite that Gallery Walk is cooperative learning strategy. Since it is a cooperative learning because students are formed in groups, they share thoughts in a more intimate and supportive setting.(http://serc.carleton.edu/introgeo/gallerywalk/what.html).

\section{Materials and methods:-}

The study adopted the quasi-experimental research where participants were match-paired based on the scores in the administered pre-test. One group was taught using gallery walk technique and the other group the traditional method of teaching. The study covered the selected topics scheduled in English subject for two quarters. Three phases were considered for the conduct of the study. The first phase was the development of learning materials, tests, and lesson plans which were submitted to the experts for validation. The second phase was the implementation involving the administration of pre-test to the learners to identify the match-pairs for the two groups. Mean scores of the two groups in the pre-test were subjected to t-test to determine if there was a significant difference in their prior knowledge before the implementation of the study. The analysis revealed that there was no significant difference, therefore there was no bias in the selection of the participants. The same sets of questions and exercises were given covering the same lessons. Quizzes as formative tests were also administered. The third phase of the study was the post-implementation where quarterly (summative) tests and post tests were given to the learners. Significant difference in the performance of learners in these tests was determined using t-test for independent means.

\section{Results and Discussion:-}

The table below illustrates the performance of the two groups in the formative tests for the two quarterly periods. For the first quarter a mean difference of 2.88 was obtained in favor of the control group. A computed t-value of 1.72 was not significant at .05 level with 48 degrees of freedom. This accepts the hypothesis that no significant difference exist in their performance during the first quarterly period. However, in the second quarterly period, the computed t-value of 2.83 suggests that there was a significant difference in their performance.

Table 1:-Formative Means of Control and Experimental Groups in the Two Quarterly Periods

\begin{tabular}{|lccc|}
\hline Groups & \multicolumn{3}{l}{} \\
Control Experimental & $\mathrm{t}$ & df & \\
\hline First Quarterly 76.44 & 73.56 & $1.72 *$ & 48 \\
Second Quarterly72.44 & 78.32 & $2.83 * 48$ & \\
\hline
\end{tabular}

Note. $*=p<.05$

In Table 2, the control group garnered a mean score of 18.76 and a standard deviation of 5.38 . The experimental group got a mean score of 22.72 with a standard deviation of 5.57. This conveys a mean difference of 3.96 in favor of the learners in the experimental group further suggesting that that they performed better than their counterpart. This is affirmed by the computed t-value of 2.56 at .05 level. 
Table 2:-Post-test Means of Control and Experimental Groups

\begin{tabular}{|llll|}
\hline $\begin{array}{l}\text { Groups } \\
\text { Control }\end{array}$ & Experimental & $\mathrm{t}$ & $\mathrm{df}$ \\
\hline Post-test & $\begin{array}{ll}18.7622 .722 .56^{*} \\
\end{array}$ & $(5.38)$ & 48 \\
& \multicolumn{4}{c|}{$(5.57)$} \\
\hline
\end{tabular}

Note. $*=p<.05$

Mean differences of 5.60 and 5.96 in the first and second quarterly periods respectively were both in favor of the experimental group's performance. As shown in Table 3, the computed t-values of 2.79 and 3.88 were significant at .05 level, therefore there was a significant difference between the performance of the two groups. It implies that learners in the experimental group performed better.

Table 3:-Quarterly (Summative) Test Means of the Control and Experimental Groups in the Two Quarterly Periods

\begin{tabular}{|c|c|c|c|c|}
\hline \multicolumn{5}{|c|}{ Groups } \\
\hline \multicolumn{5}{|c|}{ Groups } \\
\hline \multicolumn{5}{|l|}{$\begin{array}{l}\text { First Quarterly } \\
(4.26) \quad(8.87)\end{array}$} \\
\hline $\begin{array}{l}\text { Second Quarterly } \\
(4.11) \quad(6.03)\end{array}$ & 17.12 & 23.08 & $3.88^{*}$ & 48 \\
\hline $\begin{array}{lc}\text { Total } & 35.08 \\
(7.45) & (13.30) \\
\end{array}$ & 46.84 & $3.79 *$ & 48 & \\
\hline
\end{tabular}

Note. $*=p<.05$

The findings revealed significant differences in the mean scores of learners in the two groups. These are evident in the formative tests, summative or quarterly tests and the post tests. Mean differences in scores were in favor of the experimental group taught with gallery walk technique. The analysis suggests that the technique was more effective than the conventional method of teaching. Since gallery walk involves the use of multi-sensory strategies it is an effective means of bringing out the best in the students, hence optimum learning is achieved.

\section{Acknowledgements:-}

The authors would like to thank the President of Laguna State Polytechnic University, Dr. Nestor M. de Vera.

\section{References:-}

1. Bloom, B.S. (Ed.). Engelhart, M.D., Furst, E.J., Hill, W.H., Krathwohl, D.R. (1956). Taxonomy of Educational Objectives, Handbook I: The Cognitive Domain. New York: David McKay Co Inc.

2. Gagne, R. (1985). The Conditions of Learning (4th.). New York: Holt, Rinehart \& Winston.

3. http://www.gmu.edu/resources/facstaff/part-time/strategy.html

4. http://serc.carleton.edu/introgeo/gallerywalk/what.html)

5. http://www.gmu.edu/resources/facstaff/part-time/strategy.html

6. Tewksbury, B. and Heather Macdonald (2014). Online Course Design Tutorial. Retrieved from http://serc.carleton.edu/NAGTWorkshops/coursedesign/tutorial/strategies.html23April2014

7. www.deped.gov.ph. 